\title{
LA CONSTITUCIÓN ECONÓMICA A TRAVÉS DEL PLAN NACIONAL DE DESARROLLO EN MÉXICO
}

\author{
Enrique Córdoba del Valle
}

doi: 10.18543/ed-63(2)-2015pp111-126

\begin{abstract}
Sumario: 1. Antecedentes dogmático-orgánicos. 2. El «CAPÍtulo ECONÓMICO» DE LA CONSTITUCIÓN. 3. EL PLAN NACIONAL DE DESARROLLO (PND). 4. El PLAN NACIONAL DE DESARRollo 2013-2018. 5. BIBLIOGRAFÍA.
\end{abstract}

\section{ANTECEDENTES DOGMÁTICO-ORGÁNICOS}

El desarrollo revolucionario y constitucional francés de 1789, llegó a México para ejercer influencia en el texto normativo supremo.

Si bien textos anteriores, como la Constitución de Inglaterra de 1215, pueden interpretarse como una proclama de la lucha del hombre por la libertad, sin menospreciar el mérito innovador para la época en que aparecían, adolecieron de reglas que permitieran la organización y separación de los poderes públicos, como lo propondría el artículo 16 de la Declaración de los Derechos del Hombre y del Ciudadano de 1789.

La modernidad trajo consigo Constituciones garantistas de los derechos de las personas y una organización del poder. Esto justifica que tradicionalmente los contenidos esenciales de ellas se traduzcan cuando menos en dos partes, una que declara, reconoce $u$ otorga derechos a los habitantes del Estado; y otra que estructura y organiza el poder público.

Bajo este paradigma, las Constituciones escritas posteriores han establecido dos partes básicas, una dogmática y otra orgánica. 
Debe precisarse que en el caso mexicano, como lo establece Rabasa ${ }^{1}$, cada texto constitucional ha reunido varias o todas de las siguientes características:

1. Hubiera tenido alguna vigencia temporal:

2. Regido en la totalidad o buena parte del territorio mexicano;

3. Significado un rompimiento brusco con el pasado, sobre todo lo que se refiere a la forma de gobierno; $y$

4. Aportado algo nuevo o distinto en el ámbito constitucional.

La primera Constitución Política de la Nación mexicana -ya independiente-, la de 1824, tuvo el gran acierto de reorganizar al país luego de la lucha que lograría la emancipación de España. Introdujo una república representativa, popular, federal, basada en el anhelo de una estructura distinta a la de la Corona española y de que las provincias, 23 en ese momento, tuvieran la posibilidad de contar con órganos de gobierno, independientes del poder central.

En esa república federal, a decir de los ideólogos que trazaron la ruta, la Nación mexicana se conformaría como una sola, indivisible y absolutamente soberana, administrados sus intereses generales por una autoridad central cuyo ejercicio dividiría en tres órganos tradicionales de poder, un Congreso General que dictara leyes para mantener la separación de los Estados pero conservando la Unión Federal; un Supremo Poder Ejecutivo que siendo el resorte de la autoridad política fuese el depositario de toda la fuerza nacional; y un Supremo Poder Judicial encargado de dirimir discordias y oposiciones entre Estados, con atribuciones de juzgar y responsabilizar a los infractores del pacto federal ${ }^{2}$.

Se estructuró así una parte orgánica pero poco se dijo de los derechos de los mexicanos. Acaso en forma aislada e indirecta, se reconocieron derechos como la libertad política de imprenta, derechos autorales por invenciones, y reglas mínimas de orden procesal penal para garantizar el imperio de la ley, señalándose que la Nación estaba obligada a proteger por leyes sabias y justas los derechos del hombre y del ciudadano.

Nada se dijo sobre la organización económica de la Federación, con excepción de la atribución que se dio al Congreso General para fijar los gastos generales, establecer las contribuciones necesarias para cubrirlos, arreglar su recaudación, determinar su inversión y tomar anualmente cuentas al gobierno.

${ }^{1}$ RABASA, E.: Historia de las Constituciones mexicanas, Instituto de Investigaciones Jurídicas de la UNAM, México, 2000, p. 87.

2 Córdoba Del Valle, E.: El federalismo mexicano, evolución y prospectivas. Pról. Miguel Alemán Velazco, Editora del Gobierno del Estado de Veracruz, México, 2004, p.35. 
Para 1836 la república adoptó el sistema central como su forma de organización política. Las luchas ideológicas entre federalistas y centralistas, los pronunciamientos y levantamientos políticos, la separación de Tejas, el intento separatista de Yucatán, y la amenaza de intervención extranjera, provocaron un divisionismo que desprestigió el sistema federal, aunque corría la versión de que era el Presidente Santa Anna «quien encabeza la tendencia de derogar el sistema federal y establecer el centralista ${ }^{3}$, pues con él en el gobierno, se conservaba la República pero cambiaban sus formas de operación.

Así sucedió al expedirse las 7 Leyes Constitucionales del 36. En la segunda de ellas se incorporó el Supremo Poder Conservador, con amplias atribuciones para declarar la nulidad de una ley, anular los actos del Ejecutivo o de la Suprema Corte de Justicia, o incluso suspender a la Corte o restablecer constitucionalmente a los poderes que hubieren sido disueltos, es decir, un amplio sistema centralista fincado en el ejercicio de este órgano protector y revisor del orden constitucional, con la única responsabilidad ante Dios y la opinión pública.

De los derechos y obligaciones de los mexicanos se ocupó la primera ley. En ella se prescribieron derechos de orden procesal penal, derecho al voto, de expresión de ideas políticas, así como «todos los otros derechos civiles...que establezcan las leyes». Sin embargo, se trató de una época de confusión, violencia y anarquía donde aquellos, se ejercieron poco o nada.

Tampoco se dijo más sobre el aspecto económico de la Nación. A lo sumo, se atribuyó al Congreso General, la facultad de decretar anualmente los gastos que se han de hacer en el siguiente año, las contribuciones con que deben cubrirse, así como examinar y aprobar cada año la cuenta general de inversión de caudales, y aún de manera elemental, dar al gobierno bases y reglas generales para la habilitación de puertos, establecimiento de aduanas, y determinar el peso, ley, tipo y denominación de las monedas, adoptando el sistema general de pesos y medidas que le parezca. Estas funciones supondrían alguna planeación mínima de la economía del país, sin embargo, este texto constitucional de 1836 nada previó al respecto.

1843 fue el año de las Bases Orgánicas que mantuvieron el régimen central. Un dato curioso es que el Poder Ejecutivo era considerado depositario también del Poder Legislativo, en tanto le correspondía la sanción de las leyes.

Las Bases fijaron algunos derechos fundamentales como la no esclavitud, la libertad de imprenta y opinión, la inviolabilidad del domicilio, la propiedad, el libre tránsito, entre otros. Sin embargo, tampoco regularon el aspecto económico, pues solo se limitaron a atribuir al Presidente la facultad de cuidar la exactitud legal en la fabricación de la moneda, cuidar la recaudación e

${ }^{3}$ MuÑoz, R. F.: Santa Anna. El dictador resplandeciente, 4. ${ }^{\text {a }}$ ed., Fondo de Cultura Económica, México, 1996, p. 107. 
inversión de las rentas generales, así como fijar los aranceles de comercio. Estas funciones supondrían alguna planeación mínima de la economía del país, sin embargo, el texto constitucional aludido nada previó al respecto.

En suma, las Bases Orgánicas «no fueron suficientes para que el país, al fin conociera la estabilidad. Fueron calificadas como "un producto militar" que necesariamente provocó un "despotismo constitucional" $\gg^{4}$.

La vuelta al sistema federal tuvo lugar en 1847, con el nuevo triunfo de los liberales sobre los conservadores que lograron imponer el sistema federativo, basado en la reforma a la anterior Constitución de 1824 y una Acta en la que se diera forma constitutiva, naciendo así el Acta Constitutiva y de Reformas de 1847.

Bajo esta nueva organización, se reconocían como derechos de los mexicanos votar en las elecciones populares, ejercer el derecho de petición, poderse reunir para discutir los negocios públicos, y pertenecer a la Guardia Nacional, sosteniendo que para asegurar los derechos del hombre que tal Constitución expresaba, una ley fijaría las garantías de libertad, seguridad, propiedad e igualdad de que gozan todos los habitantes y los medios para hacerlas efectivas.

La estructura de gobierno regresaba a la original del 24, con la salvedad de que el cargo de Vicepresidente quedaría derogado. De esta forma, se mantuvo el gobierno republicano, representativo, popular, federal y la división de los poderes generales como de los Estados.

Sobra decir que esta Constitución tampoco diseñó un capitulado económico como los textos anteriores.

1857 marca un parteaguas en el constitucionalismo mexicano. Esta Constitución reafirma las principales decisiones políticas que contenía el federalismo de 24 , además de incorporar por primera vez de manera amplia y detallada, un capítulo especial de los derechos del hombre.

Uno de los grandes méritos de la Constitución federal de 1857 fue la modificación de las relaciones Iglesia-Estado, así como el diseño de un sistema de defensa de la Constitución. Se confirmó la república federal, una democracia representativa y se concibió a la Constitución como norma suprema del país, garantizando su vigencia permanente. Se incorporó por primera vez el amparo, como mecanismo ordinario de defensa de la supremacía constitucional.

Y por cuanto a su apartado económico, éste se limitó a considerar la prohibición de monopolios y estancos, con excepción de los relacionados con la acuñación de moneda, correos y ciertos privilegios temporales a los inventores y perfeccionadores de algunas mejoras.

${ }^{4}$ Rabasa, E., Ob. Cit.,p. 53. 
La Constitución del 57 ejerció notable influencia en la siguiente Constitución de 1917, que sigue vigente -con aproximadamente 642 reformas hasta casi fines de 2015- en México.

En 1917, los derechos del hombre pasaron a ser «garantías individuales», con un agregado importante de derechos sociales que dieron a esta Constitución una doble caracterización, liberal por influencia del 57 y social por el nuevo contenido que tuvo su origen en la Revolución mexicana de 1910.

Se mantuvo el sistema federal, el sistema presidencial, el legislativo bicameral, el judicial con mayor autonomía, el juicio de amparo, la soberanía de los Estados y el municipio libre, así como el principio de legalidad por el que todo acto de autoridad debía sujetarse a los principios normativos y constitucionales, contenidos todos que dieron forma a la parte orgánica de la Constitución.

Bajo este esquema constitucional se reforzó la figura del Ejecutivo, pero se acotó su prolongado ejercicio -dictatorial-al imponerse la no reelección $\mathrm{y}$ al eliminarse para siempre la figura de la Vicepresidencia.

La Constitución de 1917 dio un paso adelante al incorporar un apartado social, que textos posteriores tomarían como modelo o inspiración, como la de Weimar en 1919. Esa parte social prescribe un conjunto de garantías que el Estado se compromete a brindar a la colectividad.

Particular importancia revisten los artículos 3, 5, 27 y 123 que introducen derechos sociales, como el de la libertad de enseñanza, laica y gratuita; el de la libertad de trabajo y la previsión social; así como la regulación de la propiedad.

En suma, un amplio catálogo de derechos fundamentales que hicieron de la primera parte de la Constitución, una auténtica dogmática constitucional, que dicho sea de paso fue reformada en 2011 para incorporar una nueva concepción de los derechos humanos, reconocidos en la Constitución y en los tratados internacionales, normas todas conforme a las que aquellos deberán ser interpretados favoreciendo en todo tiempo a las personas la protección más amplia.

Además, esta reforma obliga a las autoridades a promover, respetar, proteger y garantizar los derechos humanos de conformidad con los principios de universalidad, interdependencia, indivisibilidad y progresividad.

El texto original de 1917 tampoco previó la dirección económica de la Nación.

Debe notarse que todos los textos constitucionales que han regido la vida de México, han cumplido expectativas específicas y temporales, casi siempre políticas y escasamente económicas.

Así, la de 1824 se encargó de reorganizar al país, aunque poco pudo hacer gracias a la pluralidad de ideologías que derivaron en una abierta inestabilidad política como signo predominante en el arranque del siglo xix. Las sub- 
secuentes Constituciones de 1836 y 43 apenas afianzaban el sistema central y veían su ocaso en el 47 con la vuelta al federalismo.

Acaso la de 1857 pueda ser la Constitución que logró una mediana estabilidad político-liberal; sin embargo, la breve irrupción del segundo imperio con Maximiliano en 1863-67 y los movimientos preparatorios de la revolución que se avecinaba, influyeron para que tampoco se garantizara una permanencia pacífica de régimen político alguno.

Quiero decir que se dio importancia, por conveniencia o estrategia, a la toma de decisiones políticas que poco tenían que ver con una sostenida planeación del desarrollo nacional. No había tiempo, más que para realizar un tejido de alianzas que llevaran a permanecer en el poder.

No fue sino hasta el régimen del presidente Porfirio Díaz, reconocido estratega militar y político, cuando en México logró percibirse un auténtico cambio hacia el progreso, quizá porque se mantuvo en el poder presidencial por un periodo de 34 años, entre 1876 y 1911, con algunas breves interrupciones.

Con mano dura logró progresivamente la pacificación del país. Mantuvo buena relación política con los gobernadores de los Estados y los jefes militares, porque en la mayoría de los casos se trataba de militares de su confianza a quienes él mismo colocaba en esas posiciones.

Uno de los avances más significativos de la época de Díaz en la presidencia fue, la construcción de ferrocarriles que pronto ayudaría a extender el comercio por más lugares del país y del extranjero, cuando se abrieron rutas claves como la México-Veracruz y otras hacia la frontera con Estados Unidos.

El florecimiento de la cultura y el desarrollo de la ciencia, a través de la fundación de escuelas y bibliotecas, el aumento de la inversión extranjera, la electrificación del país, la industria de transportes y comunicaciones como la adopción del telégrafo y el teléfono, la instalación de correos, la creación de plantas hidroeléctricas y el descubrimiento de reservas de petróleo, entre otros, fueron factores que incidieron en el desarrollo económico que impulsaba el presidente.

Sin embargo, en su afán por aumentar la producción agrícola, Díaz vulneró los derechos de los campesinos y obreros, al forzar los trabajos a periodos prolongados por más de 14 horas diarias y mediante un sistema de pagos denominado «tiendas de raya», donde se canjeaban productos y alimentos básicos por vales que los patrones, mayoritariamente dueños de las grandes haciendas o fábricas, les proporcionaban. Además, de la prohibición para que los trabajadores formaran organizaciones o se manifestaran, so pena de imposición de multas o cárcel en caso de desobediencia.

Junto con la crisis económica que devino en 1908, la exigencia de mejoramiento de derechos laborales por la clase obrera, las huelgas de Cananea, Sonora en 1906 y de Río Blanco, Veracruz en 1907, el régimen de Díaz de- 
caía y las primeras muestras de inestabilidad social llevarían más a tarde a la revolución de 1910.

No volvió a darse una planeación nacional del desarrollo, con el empuje que tuvo la época porfirista, en la práctica ni en el texto constitucional -incluido el de 1917- sino hasta la década de los ochenta. Quizá en los años 30 bajo la presidencia de Lázaro Cárdenas pero no es fácil ubicar tal antecedente.

Fue hasta el 3 de febrero de 1983, cuando el presidente de México, Miguel de la Madrid, reformó la Constitución Política incorporando lo que la doctrina mexicana ha llamado parte programática o «Capítulo económico» de la misma, debido a la naturaleza de su contenido al establecer las normas básicas para regular la planeación y programación del desarrollo nacional a través de los diversos programas que elabora la administración pública.

En otras palabras, la parte programática precisa las principales atribuciones del Estado para hacerse cargo de la rectoría económica del país, reservándose el aprovechamiento de ciertas áreas y actividades consideradas estratégicas o prioritarias, teniendo la responsabilidad de dirigir la planeación del desarrollo nacional.

Si bien nuestra Constitución en forma aislada contiene disposiciones que pueden inferirse relacionadas con aspectos económicos, son los artículos 25 , 26 y 28, los que a pesar de ubicarse en la sección de los derechos humanos, dan sentido a un «apartado económico» porque sus contenidos se refieren esencialmente a la estructura y funcionamiento de la actividad económica estatal.

\section{EL «CAPÍTULO ECONÓMICO» DE LA CONSTITUCIÓN}

El artículo 25 de la Constitución regula la rectoría de la actividad económica nacional.

Dispone que corresponde al Estado mexicano la rectoría del desarrollo nacional para garantizar que éste sea integral y sustentable, que fortalezca la soberanía nacional y su régimen democrático; y que, mediante la competitividad, el fomento del crecimiento económico, el empleo y una más justa distribución del ingreso y la riqueza, permita el pleno ejercicio de la libertad y la dignidad de los individuos, grupos y clases sociales, cuya seguridad protege la Constitución.

La competitividad queda definida en este artículo, como el conjunto de condiciones necesarias para generar un mayor crecimiento económico, promoviendo la inversión y la generación de empleo.

A partir del 26 de mayo de 2015 se incorporó la previsión de que corresponde al Estado, velar por la estabilidad de las finanzas públicas y del sistema financiero para coadyuvar a generar condiciones favorables para el crecimiento económico y el empleo. Y se establece que el mecanismo 
jurídico-administrativo para cumplir este imperativo constitucional, es la elaboración del Plan Nacional de Desarrollo y los planes estatales y municipales respectivos.

Es importante destacar que es al Estado a quien corresponde planear, conducir, coordinar y orientar la actividad económica nacional, y que éste hace un llamado para que concurran al desarrollo económico nacional -con responsabilidad social-, el sector público, el sector social y el sector privado, sin menoscabo de otras formas de actividad económica que contribuyan al desarrollo de la Nación.

Además, enfatiza que el Estado ejerce predominio en forma exclusiva, sobre las áreas estratégicas a que se refiere el artículo 28, pero es el Gobierno Federal quien mantendrá siempre la propiedad y el control sobre los organismos y empresas productivas del Estado que en su caso se establezcan.

Materias como el sistema eléctrico nacional, el servicio público de transmisión y distribución de energía eléctrica, la exploración y extracción de petróleo y demás hidrocarburos, quedan reservadas al Estado para que éste las lleve a cabo según el artículo 27 constitucional, en que se regula la propiedad de la Nación.

Finalmente, se señala que la ley alentará y protegerá la actividad económica de los particulares, proveerá condiciones para que el sector privado contribuya al desarrollo económico nacional, promoverá la competitividad e implementará una política nacional para el desarrollo industrial sustentable.

El artículo 26 constitucional contiene tres apartados que concurren a un mismo fin: la rectoría del desarrollo nacional.

En el apartado A, se dispone que el Estado organizará un sistema de planeación democrática y deliberativa del desarrollo nacional, y que será mediante mecanismos de participación legal como recogerá las aspiraciones y demandas de la sociedad para incorporarlas al Plan Nacional de Desarrollo y los programas de desarrollo, el primero de ellos obligatorio para los programas de la Administración Pública Federal. En este sistema, señala, el Congreso de la Unión tendrá la intervención que disponga la ley.

En el apartado B, se regula la existencia del Sistema Nacional de Información Estadística y Geográfica, a cargo del Instituto Nacional de Estadística y Geografía (INEGI) cuya información y datos que genera, además de oficiales serán de uso obligatorio.

En el apartado C, se contempla la existencia del Consejo Nacional de Evaluación de la Política de Desarrollo Social (CONEVAL), órgano autónomo encargado de la medición de la pobreza y de la evaluación de los programas, objetivos, metas y acciones de la política de desarrollo social, así como de emitir recomendaciones en los términos que disponga la ley, la cual establecerá las formas de coordinación del órgano con las autoridades federales, locales y municipales para el ejercicio de sus funciones. 
El artículo 28 de la Constitución está referido ampliamente a la prohibición de monopolios, prácticas monopólicas, estancos y exenciones de impuestos.

El objetivo central de estas disposiciones es eliminar toda concentración o acaparamiento en una o pocas manos de artículos de consumo necesario y que tenga por objeto obtener el alza de los precios; evitar la libre concurrencia o la competencia entre sí o para obligar a los consumidores a pagar precios exagerados y, en general, todo lo que constituya una ventaja exclusiva indebida a favor de una o varias personas determinadas y con perjuicio del público en general o de alguna clase social, es decir, la competencia desleal.

Por esta razón, se atribuye como competencia del Estado fijar bases para que se señalen precios máximos a los artículos, materias o productos que se consideren necesarios para la economía nacional o el consumo popular, así como para imponer modalidades a la organización de la distribución de esos artículos, materias o productos, a fin de evitar que intermediaciones innecesarias o excesivas provoquen insuficiencia en el abasto, así como el alza de precios. Se trata a todas luces de medidas legales que protejan a los consumidores y propicien su organización para el mejor cuidado de sus intereses.

Sin embargo, se considera que no constituyen monopolios y por tanto corresponde al Estado ejercer sus funciones de manera exclusiva, tanto en las áreas estratégicas como en las áreas prioritarias.

Según este mismo artículo 28 , se consideran áreas estratégicas, los correos, telégrafos y radiotelegrafía; minerales radiactivos y generación de energía nuclear; la planeación y el control del sistema eléctrico nacional, así como el servicio público de transmisión y distribución de energía eléctrica, y la exploración y extracción del petróleo y de los demás hidrocarburos, en los términos del artículo 27 constitucional. La comunicación vía satélite y los ferrocarriles son áreas prioritarias para el desarrollo nacional en los términos del artículo 25 constitucional. Al ejercer en ellas su rectoría, el Estado protegerá la seguridad y la soberanía de la Nación, y al otorgar concesiones o permisos mantendrá o establecerá el dominio de las respectivas vías de comunicación de acuerdo con las leyes de la materia.

Para el eficaz manejo de las áreas estratégicas a su cargo y en las actividades de carácter prioritario donde participe por sí o con los sectores social y privado, el Estado contará con los organismos y empresas que requiera.

Especialmente, el artículo 28 constitucional se refiere a los siguientes.

Un Banco Central. Autónomo en sus funciones y en su administración, tendrá como objetivo procurar la estabilidad del poder adquisitivo de la moneda nacional, fortaleciendo con ello la rectoría del desarrollo nacional que corresponde al Estado.

Debe señalarse que este Banco de México o Banxico como se le denomina cotidianamente, participa como institución fiduciaria del Estado, en el 
Fideicomiso público denominado Fondo Mexicano del Petróleo para la Estabilización y el Desarrollo, cuyo objeto es recibir, administrar y distribuir los ingresos derivados de las asignaciones y contratos a que se refiere el párrafo séptimo del artículo 27 constitucional, es decir, los relativos a las actividades de exploración y extracción del petróleo y demás hidrocarburos.

También se dispone, desde el artículo 28 constitucional, que no constituyen monopolios las funciones que el Estado ejerza de manera exclusiva, a través del Banco Central en las áreas estratégicas de acuñación de moneda y emisión de billetes; las asociaciones de trabajadores formadas para proteger sus propios intereses y las asociaciones o sociedades cooperativas de productores para que vendan directamente en los mercados extranjeros los productos nacionales o industriales que sean la principal fuente de riqueza de la región en que se produzcan o que no sean artículos de primera necesidad; ni los privilegios que por determinado tiempo se concedan a los autores, artistas, inventores y perfeccionadores para la producción de sus obras y uso exclusivo de sus inventos.

Además, en materia energética, el Poder Ejecutivo se apoyará con los órganos reguladores denominados Comisión Nacional de Hidrocarburos y Comisión Reguladora de Energía.

El Estado contará también con una Comisión Federal de Competencia Económica, órgano autónomo encargado de garantizar la libre competencia y concurrencia, así como prevenir, investigar y combatir los monopolios, las prácticas monopólicas, las concentraciones y demás restricciones al funcionamiento eficiente de los mercados, que planea la misma Constitución.

Un Instituto Federal de Telecomunicaciones, también autónomo, cuyo objeto será el desarrollo eficiente de la radiodifusión y las telecomunicaciones, teniendo a su cargo la regulación, promoción y supervisión del uso, aprovechamiento y explotación del espectro radioeléctrico, las redes y la prestación de los servicios de radiodifusión y telecomunicaciones, así como del acceso a infraestructura activa, pasiva y otros insumos esenciales.

En suma, una serie de disposiciones que en tan solo tres artículos constitucionales, plantean el modelo normativo del desarrollo económico de la Nación, con objetivos, instituciones y principios que tienen que ser obedecidos por el rango federal que poseen.

Con las disposiciones que este «capítulo económico» plantea, se desprende que si bien el Estado no es precisamente quien debe estar a cargo de toda la administración de manera directa, sí es responsable de guiar y orientar el desarrollo del país para fortalecer la soberanía nacional, cuya seguridad protege la Constitución como uno de sus mayores objetivos.

$\mathrm{Y}$ es precisamente a través de instrumentos como el Plan Nacional de Desarrollo, como el Estado responde a las aspiraciones y demandas ciudada- 
nas, al organizar un sistema de planeación democrática y deliberativa del desarrollo nacional, para conducir, coordinar y orientar su gran responsabilidad por la rectoría económica del país.

\section{EL PLAN NACIONAL DE DESARROLLO (PND)}

El Plan Nacional de Desarrollo (PND) es un instrumento normativo, de carácter administrativo, de que se vale el Poder Ejecutivo para enmarcar las principales acciones y estrategias que desarrollará, durante el ejercicio de su función que dura seis años, con el apoyo de la Administración Pública que él dirige. Su vigencia no excederá del período constitucional, lo que no obsta para que pueda contener consideraciones y proyecciones de más largo plazo.

Surge de un amplio proceso que es dirigido por la Secretaría de Hacienda y Crédito Público, a quien el Ejecutivo encarga directamente su coordinación. El proceso de elaboración, aprobación y publicación, se desarrolla en un periodo de seis meses, que se inicia a partir de la toma de protesta del cargo del Presidente de la República.

Así lo establece la Ley de Planeación, en cuyo artículo 14 fracción II atribuye a la Secretaría de Hacienda elaborar el PND tomando en cuenta las propuestas de las dependencias y entidades de la Administración Pública Federal y de los gobiernos de los estados, los planteamientos que se formulen por los grupos sociales y por los pueblos y comunidades indígenas interesados, así como la perspectiva de género.

En forma detallada, el artículo 20 de la Ley de Planeación señala la participación y consulta de los diversos grupos sociales, con el propósito de que la población exprese sus opiniones. Así, organizaciones de obreros, campesinos, pueblos y grupos populares; instituciones académicas, profesionales y de investigación de los organismos empresariales; y otras agrupaciones sociales, participarán como órganos de consulta permanente en los aspectos de la planeación democrática relacionados con su actividad a través de foros de consulta popular que al efecto se convocarán, donde incluso participarán también los diputados y senadores del Congreso de la Unión.

Las comunidades indígenas deberán ser consultadas y podrán participar en la definición de los programas federales que afecten directamente el desarrollo de sus pueblos y comunidades.

Según el artículo 83 constitucional, el Presidente entrará a ejercer su encargo el $1 .^{\circ}$ de diciembre de cada seis años, sin embargo, una reciente reforma dada el 10 de febrero de 2014 que será aplicable hasta diciembre de 2018, ha dispuesto que el periodo presidencial 2018-2024 inicie el 1. ${ }^{\circ}$ de diciembre y concluya el 30 de septiembre, para reiniciar el $1 .^{\circ}$ de octubre de 2024 con la misma duración de seis años. 
De esta manera, el PND de 2018 deberá estar listo a más tardar el 1. ${ }^{\circ}$ de junio de 2019 y el PND de 2024 a más tardar el $1 .^{\circ}$ de abril de 2025, en ambos casos, en un plazo de seis meses después de iniciado el mandato presidencial, como lo establece el artículo 21 de la Ley de Planeación.

El objetivo esencial del PND es diseñar el conjunto de estrategias y prioridades que han de desarrollarse para la consecución de los grandes objetivos nacionales, es decir, las metas y acciones que se emprenderán durante los próximos seis años.

La Ley de Planeación establece en el segundo párrafo del artículo 21, que el PND precisará los objetivos nacionales, estrategia y prioridades del desarrollo integral y sustentable del país, contendrá previsiones sobre los recursos que serán asignados a tales fines; determinará los instrumentos y responsables de su ejecución, establecerá los lineamientos de política de carácter global, sectorial y regional; sus previsiones se referirán al conjunto de la actividad económica, social y cultural, tomando siempre en cuenta las variables ambientales que se relacionen a éstas y regirá el contenido de los programas que se generen en el sistema nacional de planeación democrática.

Una de las ventajas que entraña per se el PND es la rendición de cuentas. En los últimos años, en México se han venido incrementando las experiencias de una gestión pública cada vez más transparente, pues la sociedad reclama con mayor insistencia que se le informe de los actos del gobierno y del ejercicio racional y transparente de los recursos públicos, forzando al gobierno a ceder con la creación de instancias y mecanismos de acceso a la información, a nivel federal como en los estados.

El PND, una vez elaborado, es remitido a la Cámara de Diputados del Congreso de la Unión para su examen y opinión. Este órgano deliberativo, en ejercicio de la atribución que le confiere el artículo 74 fracción VII de la Constitución, por cierto reformado también el 10 de febrero de 2014, lo aprueba en el plazo que disponga la ley; sin embargo, está previsto que en caso de no pronunciarse en dicho plazo, el PND se entenderá aprobado.

Una vez aprobado el PND se publicará en el Diario Oficial de la Federación, lo que sucederá también con los programas sectoriales que de él deriven, y que se encuentran previstos en el artículo 22 de la referida Ley de Planeación. De igual forma existen otros programas, como los institucionales, regionales y especiales que se elaboran siempre en congruencia o «alineados» con el PND.

La característica de los programas sectoriales que derivan del PND es que tienden a especificar los objetivos, prioridades y políticas que regirán el desempeño de las actividades del sector administrativo de que se trate, conteniendo estimaciones de recursos y determinaciones sobre instrumentos y responsables de su ejecución, entre otros elementos. 


\section{EL PLAN NACIONAL DE DESARROLLO 2013-2018}

El Plan Nacional de Desarrollo 2013-2018, cuya ejecución está a cargo de la Administración Pública que encabeza el presidente Enrique Peña Nieto, se define como un documento de trabajo que rige la programación y presupuestación de la Administración federal, y un ejercicio de reflexión que invita a la ciudadanía a pensar sobre los retos y oportunidades que el país enfrenta, además de ser un canal de comunicación del gobierno de la República.

Está estructurado bajo un objetivo general, cinco metas nacionales y tres ejes transversales, así como 31 objetivos, 118 estrategias y 819 líneas de acción. Para medir la productividad del trabajo, la rendición de cuentas, la modernización del gobierno y la igualdad de género se estableció un apartado de Indicadores.

El objetivo general del PND es llevar a México a su máximo potencial, entendiendo que la estrategia general para lograrlo se funda en impulsar el dinamismo de una mayor productividad.

Se trata de elevar la productividad de la economía en su conjunto, aprovechando el empuje de la innovación y el desarrollo tecnológico. Para ello será necesario movilizar los factores de producción y asignarlos a sus usos más productivos, contar con un entorno de negocios en el que se eviten las cargas regulatorias excesivas, exista una competencia plena en sectores estratégicos de la economía, se brinde garantía jurídica y se salvaguarde la integridad física de la población, respaldado por un gobierno eficaz, ágil y moderno.

Las cinco metas nacionales se describen como sigue:

1. Un México en Paz que garantice el avance de la democracia, la gobernabilidad y la seguridad de su población. Esta meta busca fortalecer las instituciones mediante el diálogo y la construcción de acuerdos con actores políticos y sociales, la formación de ciudadanía y corresponsabilidad social, el respeto y la protección de los derechos humanos, la erradicación de la violencia de género, el combate a la corrupción y el fomento de una mayor rendición de cuentas, todo ello orientado a la consolidación de una democracia plena.

2. Un México Incluyente para garantizar el ejercicio efectivo de los derechos sociales de todos los mexicanos, que vaya más allá del asistencialismo y que conecte el capital humano con las oportunidades que genera la economía en el marco de una nueva productividad social, que disminuya las brechas de desigualdad y que promueva la más amplia

${ }^{5}$ El contenido de este apartado está referido al Plan Nacional de Desarrollo mexicano, para el ejercicio presidencial 2013-2018, y que se encuentra en http://pnd.gob.mx/, consultada el 3 de diciembre de 2015. 
participación social en las políticas públicas como factor de cohesión y ciudadanía.

3. Un México con Educación de Calidad para garantizar un desarrollo integral de todos los mexicanos y así contar con un capital humano preparado, que sea fuente de innovación y lleve a todos los estudiantes a su mayor potencial humano.

4. Un México Próspero que promueva el crecimiento sostenido de la productividad en un clima de estabilidad económica y mediante la generación de igualdad de oportunidades. Lo anterior considerando que una infraestructura adecuada y el acceso a insumos estratégicos fomentan la competencia y permiten mayores flujos de capital y conocimiento hacia individuos y empresas con el mayor potencial para aprovecharlo.

Asimismo, esta meta busca proveer condiciones favorables para el desarrollo económico, a través de una regulación que permita una sana competencia entre las empresas y el diseño de una política moderna de fomento económico enfocada a generar innovación y crecimiento en sectores estratégicos.

5. Un México con Responsabilidad Global que sea una fuerza positiva y propositiva en el mundo, una Nación al servicio de las mejores causas de la humanidad. Nuestra actuación global debe incorporar la realidad nacional y las prioridades internas, enmarcadas en las otras cuatro Metas Nacionales, para que éstas sean un agente definitorio de la política exterior.

De igual forma, el PND plantea tres estrategias transversales:

1. Democratizar la productividad. Implica llevar a cabo políticas públicas que eliminen los obstáculos que impiden alcanzar su máximo potencial a amplios sectores de la vida nacional. Asimismo, significa generar los estímulos correctos para integrar a todos los mexicanos en la economía formal; analizar de manera integral la política de ingresos y gastos para que las estrategias y programas de gobierno induzcan la formalidad; e incentivar, entre todos los actores de la actividad económica, el uso eficiente de los recursos productivos.

2. Gobierno cercano y moderno. Las políticas y acciones de gobierno inciden directamente en la calidad de vida de las personas, por lo que es imperativo contar con un gobierno eficiente, con mecanismos de evaluación que permitan mejorar su desempeño y la calidad de los servicios; que simplifique la normatividad y trámites gubernamentales, y rinda cuentas de manera clara y oportuna a la ciudadanía.

3. Perspectiva de género. La presente Administración considera fundamental garantizar la igualdad sustantiva de oportunidades entre mujeres y hombres. 
Finalmente, debe señalarse que para lograr el proyecto de Nación que plantea el PND, el presidente de la República ha impulsado un paquete de reformas constitucionales que ha denominado «reformas estructurales» con el objetivo de hacer viable la gran transformación de México.

Sobre los resultados alcanzados hasta el momento, a tres años de gobierno, consideramos será prudente esperar a la conclusión del mandato presidencial para estar en condición de evaluar el impacto que la gestión del gobierno federal ha logrado en lo que el Ejecutivo denomina «Mover a México».

\section{BIBLIOGRAFÍA}

CóRdoba Del VAlle, E.: El federalismo mexicano, evolución y prospectivas. Pról. Miguel Alemán Velazco, Editora del Gobierno del Estado de Veracruz, México 2004.

MuÑOz, Rafael F.: Santa Anna. El dictador resplandeciente, 4. ${ }^{\text {a }}$ ed., Fondo de Cultura Económica, México 1996.

RABASA, E.: Historia de las Constituciones mexicanas, Instituto de Investigaciones Jurídicas de la UNAM, México 2000.

Plan Nacional de Desarrollo 2013-2018, Gobierno de la República, en http://pnd.gob.mx/

TITTLE: The Economic Constitution through the NDP in México.

RESUMEN: La evolución de las Constituciones Políticas de México, muestra una ausencia de planeación económica del desarrollo nacional, al menos durante el siglo xix.

La Constitución de 1917, si bien impulsó por primera vez en el mundo el reconocimiento de derechos sociales básicos, careció de un apartado económico que no llegó sino hasta los años ochenta, cuando incorporó en su texto, una parte programática o capítulo económico que delinea cómo se construyen las principales acciones y estrategias para impulsar el desarrollo.

Es a través del Plan Nacional de Desarrollo, instrumento normativo de la administración Pública, como el Estado ejerce su responsabilidad de planear, conducir, coordinar y orientar la actividad económica nacional.

Este análisis detalla cómo se construye el Plan de Desarrollo y cuáles son sus contenidos actuales.

PALABRAS ClaVE: Constitución económica-Planeación-Desarrollo.

ABSTRACT: The evolution of Mexico's Political Constitutions, shows an absence of economic planning of national development, at least during the $19^{\text {th }}$ century.

The Constitution of 1917, though it stimulated for the first time in the world the recognition of social basic rights, lacked an economic para- 
graph that did not come but until the eighties, when it incorporated in its text, a programmatical part or economic chapter that delineates how the principal actions and strategies are constructed to stimulate the development.

It is across the National Development Plan, normative instrument of the public administration, as State exercises its responsibility of gliding, driving, coordinating and orientating the economic national activity.

This analysis details how there is constructed the National Development Plan and which are its current contents.

KEYWORDS: Economic Constitution-Planning-Development.

RECIBIDO: 26.11.2015

ACEPTADO: 09.12.2015 